\title{
Teaching Bioterrorism Preparedness with Simulation - The Pneumonic Plague Example
}

\section{Martin Olsen*}

Department OB/GYN, East Tennessee State University, P.O. Box 70569, USA

\begin{abstract}
Future bioterrorism acts are an unfortunate possibility for which healthcare providers and medical systems must prepare. Plague, caused by Yersinia pestis, is a potential bioterrorism agent which healthcare providers in the developed world have only a low familiarity. This article provides a teaching strategy using medical simulation to assist healthcare professionals and institutions in preparing for bioterrorism events.
\end{abstract}

Keywords: Medical simulation; Bioterrorism; Pneumonic plague

\section{Introduction}

Yersinia pestis is the etiologic agent for plague, one of the category A potential biologic weapons as categorized by the Center for Disease Control and Prevention. Category A infections (1) can be easily transmitted from person to person (2) result in high mortality rates (3) may cause public panic and disruption and (4) require special action for public health preparedness.

Yersinia pestis infection most commonly can manifest itself in three different fashions:

1. Bubonic plague: an infection transmitted by flea bites with rodent vectors. Contact with infected animals causes human risk.

2. Septicemic plague: a blood borne infection.

3. Pneumonic plague: a form of infection which can be transmitted person to person by respiratory droplets. It is the pneumonic plague version which is the most likely biologic weapon in that an aerosolized form could infect primary victims found in a confined area and these primary victims could then infect secondary victims. In the natural disease, pneumonic plague can also be secondary to bubonic plague or septicemic plague.

The large outbreaks of pneumonic plague in its natural form that have occurred in the past $[1,2]$ provide the only available clinical experience with human pneumonic plague. Intentional dissemination of plague could occur by aerosolized Yersinia pestis. This mechanism has been shown to produce disease in nonhuman primates [3]. The first signs of illness expected would be fever with cough with the production of bloody, watery, or purulent sputum, and dyspnea [3]. Prominent gastrointestinal symptoms including nausea, vomiting, abdominal pain, and diarrhea may also be present $[4,5]$. Chest X-ray findings are variable but bilateral infiltrates or consolidation are usually seen with a propensity for the lower lobes; mediastinal and hilar adenopathy may also be seen [6,7]. Patients with pneumonic plague deteriorate very rapidly. Early diagnosis is extremely important for patient survival. Therefore frontline healthcare providers should have training in the diagnosis and management of bioterrorism agents such as pneumonic plague. Suboptimal physician training in bioterrorism preparedness has been described $[8,9]$. This article seeks to provide a mechanism to improve bioterrorism preparedness.

This article describes a simulation based training format. In a simulation based format, physicians have an opportunity to work with simulated patients, make a diagnosis, and design a treatment plan in a more realistic process than traditional lecture based training.
The use of simulation in medical education has increased dramatically over the last decade. Evidence supports simulation's role in patient safety improvement [10]. Many medical students and residents in training have a simulation component to their education on a regular basis. Modern simulation includes the use of high-fidelity patient simulators which have the appearance of human beings; they have blinking eyes, have heart sounds, lung sounds, and pulses (Figure 1). These simulators can demonstrate "patient" improvement when proper treatment is administered and they can deteriorate when a diagnosis is missed or the treatment regimen is suboptimal. Simulation based training has been shown to have significant advantages over traditional training in multiple areas [11-16]. Bioterrorism of course is such a rare

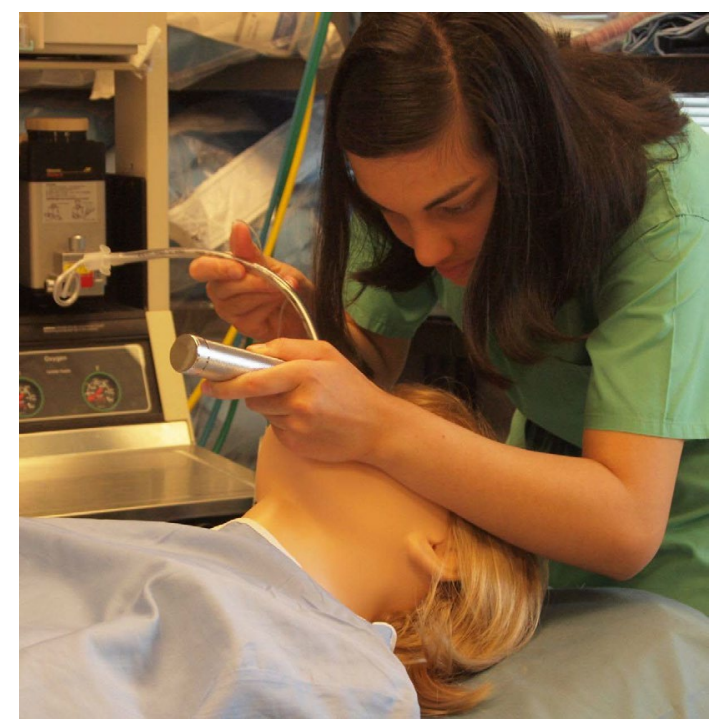

Figure 1: A student intubates a simulated patient.

*Corresponding author: Martin Olsen, Department of OB/GYN, Johnson City, TN 37614-1707, USA, Tel: 423439 8755; Fax: 423 439-6766; E-mail: olsen@etsu.edu

Received May 25, 2013; Accepted December 15, 2013; Published January 02, 2014

Citation: Olsen M (2014) Teaching Bioterrorism Preparedness with Simulation - The Pneumonic Plague Example. J Clin Res Bioeth 5: 164. doi:10.4172/21559627.1000164

Copyright: (c) 2014 Olsen M. This is an open-access article distributed under the terms of the Creative Commons Attribution License, which permits unrestricted use, distribution, and reproduction in any medium, provided the original author and source are credited. 
occurrence that no evidence based comparisons can be made at this time. The use of medical simulation to train learners in other topics of potential terrorist acts has been previously described $[17,18]$.

\section{Background: Pneumonic Plague}

The fatality rate for patients with pneumonic plague when treatment is delayed for greater than twenty-four hours is extremely high [19]. This observation highlights the importance of ensuring that physicians who make contact with pneumonic plague victims have an opportunity to make a lifesaving diagnosis. Patients with pneumonic plague had dyspnea, chest pain, and a cough that can produce bloody sputum [20]. Pneumonic plague progresses rapidly and is usually fatal without prompt treatment [20]. Fulminant pneumonia often associated with disseminated intravascular coagulation, shock, and multi-organ failure, follows after an incubation period of 1-6 days [21]. The same 1-6 day course is anticipated for weaponized plague [22]. This severe pneumonia may also present with the addition of gastrointestinal symptoms such as abdominal pain, vomiting, and diarrhea [21]. Aerosolized plague might also result in rare pharyngeal plague or ocular plague [23].

In a community a experiencing a pneumonic plague epidemic, all persons developing a temperature of $38.5^{\circ} \mathrm{C}$ or greater or a new cough should begin antibiotic treatment. Diagnosis of pneumonic plague may be made by the culture of the organism from the sputum or blood. Cultures can be positive within 24-28 hrs [24]. CDC guidelines point out that streptomycin is the preferred treatment for plague and is Food and Drug Administration approved for this indication, but may not be readily available in a mass casualty situation. Gentamycin is an off label second choice. Other alternatives include tetracyclines, chloramphenicol, and fluoroquinolones [23]. For mass casualty post exposure prophylaxis, doxycycline and ciprofloxacin are recommended. Credible reports exist that the former Soviet Union engineered multi-drug resistant Yersinia pestis as a part of its biological weapons program [25]; close follow-up for antibiotic effectiveness would be appropriate.

Patients typically require aggressive fluid resuscitation and may need vasopressors, hemodynamic monitoring, and mechanical ventilation. Symptomatic patients should be isolated with respiratory precautions; this includes gowns, gloves, and eye protection as well as disposable surgical masks.

Physician diagnosis and management of diseases caused by bioterrorism agents has been described as poor [26]. Physicians in the developed world most likely have never seen a case of pneumonic plague. In the US patient deaths from pneumonic plague contracted from domestic cats have been described [5,27,28], but the last person-to-person transmission of plague in the United States was reported in $1925[20,23]$. For these reasons it is appropriate to consider new educational formats such as medical simulation to prepare healthcare providers for a potential bioterrorism attack with weaponized plague.

\section{Discussion 'Simulation Training'}

The scenario described in this article is a more difficult scenario than the skills and drills exercises frequently encountered in many simulation labs. In medical training today, learners are closely supervised; this decreases the chance of error. This close supervision however does not, in many cases, allow for the learner to function at the level of his or her capacity. The author has found that learners appreciate the challenge of the simulation lab where they can feel proud of their efforts when they successfully make a diagnosis. When the diagnosis is missed they have had an opportunity to learn and reflect. The reset button on the patient simulator can be selected and a do over can occur unlike with real patients. It is therefore the author's philosophy that simulation should be as challenging as the learners can handle. Learners are advised before they initiate a scenario that patients in the simulation lab have a higher mortality rate than the general population. Learners have expressed satisfaction that the exercises are appropriately challenging.

When this scenario is used, it is recommended that the participants enter the activity without previous warnings on the topic of discussion. If they make the correct diagnosis they must then also struggle with the selection of the proper antibiotic treatment and notification of appropriate officials.

Scenario components are listed in Table 1 , which can be used as a "tear out" for simulation lab directors who wish to use this template in a teaching exercise. These components include learning objectives. The simulation overview is used by the simulation director to plan the educational activity. Learners of course will enter this environment without knowledge of the differential diagnosis; review of the patient history and exam by the simulation director with the person portraying the voice of the patient and the actor/actress portraying the family members is important to complete prior to the initiation of the scenario. Laboratory studies will be made available to the participants when they ask for these individual results. Simulation parameters are the settings which are used to allow the patient simulator to realistically project the simulation patient's status. Expected actions by participants can help lead the discussion of the debrief session as the participants review their strengths and weaknesses. Table 1 also includes a list of personnel and props which provide the simulation lab director a list of those individuals and items the simulation director will require in order to successfully run the scenario. The debriefing points contribute to the discussion after the scenario. The scenario itself usually takes about fifteen or twenty minutes to run. Set-up time can easily be two or three hours.

The debrief session is the most important part of the exercise. This is the time that the learners can discuss their successes, discuss the areas in which they could have improved, and provide self-critique. The facilitator should promote discussion among the participants, not give a lecture [29-31]. It is important that the debrief session be run in a fashion so that the learners are aware of their limitations but also are not traumatized by any failure which might occur. A comprehensive debrief session frequently lasts 30 to 45 minutes.

When this scenario was run with medical students at the author's institution, the students were unable to make the correct diagnosis. They recognized the simulated illness as consistent with a serious pulmonary infection, but failed to initiate respiratory precautions such as masks for themselves and the simulated patient. The debrief discussion included the observation that the diagnosis was difficult and that student inability to make the diagnosis was not a surprise. The debriefing conversation included mechanisms to improve differential diagnosis formation. The students verbalized observations that the simulation exercise was valuable and those they felt they would be more likely to initiate respiratory precautions in the future with real patients who present with apparent pulmonary infections.

\section{Conclusion}

Pneumonic plague is a significant potential bioterrorism agent which could be released onto an unsuspecting public via an aerosolized 
Citation: Olsen M (2014) Teaching Bioterrorism Preparedness with Simulation - The Pneumonic Plague Example. J Clin Res Bioeth 5: 164 doi:10.4172/2155-9627.1000164

\begin{tabular}{|c|c|}
\hline Learning objectives & $\begin{array}{l}\text { - Realize that all frontline medical care providers should be familiar with bioterrorism concepts such as preparedness, recognition and } \\
\text { reporting to healthcare authorities } \\
\text { - Initiate management of a critically ill simulated patient with unknown diagnosis } \\
\text { - Create a differential diagnosis which includes pneumonic plague } \\
\text { - Manage pneumonic plague }\end{array}$ \\
\hline Patient history and exam & $\begin{array}{l}\text { The patient is a } 39 \text {-year-old who presents to the healthcare facility with fever, shortness of breath and a productive cough with bloody } \\
\text { sputum. She was in good health until just several hours ago. } \\
\text { She also experiences headache, nausea, and vomiting. The patient is a manager in a high end retail store and lives in a middle class } \\
\text { apartment complex with her husband. She does not have a pet. Past medical history shows no other hospitalizations. She has never } \\
\text { had surgery. She denies tobacco. She denies ethanol use. She has no known drug allergies. She is at this healthcare facility with her } \\
\text { husband and sister who are also coughing although they are not febrile and do not appear ill. } \\
\text { Exam shows an uncomfortable patient. She is wearing a cap with the logo from a local sporting team. A little bit of blood is seen exiting } \\
\text { her mouth after one of her coughs. Temperature is } 103.1^{\circ} \text {. } \\
\text { Pulmonary exam shows significant rales and rhonchi. Pulse is } 110 \text {. } \\
\text { Respirations are } 28 \text {. Social history shows that she attended a major sporting event } 3 \text { days ago. }\end{array}$ \\
\hline Labs & CBC-wbc $=19,000, \mathrm{hgb}=14.5 \mathrm{hct}=42$ platelets $=174,000$ \\
\hline Simulation parameters & $\begin{array}{l}\text { - Temperature }=103 \cdot 1^{\circ} \mathrm{F} \text {. Pulse }=110 . \mathrm{R}=28 . \mathrm{BP}=105 / 75 \\
\text { - A little bit of simulated blood should be placed at the corner of the patient's mouth to demonstrate hemoptysis } \\
\text { - Pulmonary exam reveals significant rales and rhonchi throughout the exam. }\end{array}$ \\
\hline Expected actions by participants & $\begin{array}{l}\text { - Realize that the patient is extremely ill. } \\
\text { - With physical exam, identify lungs as the likely source of infection. } \\
\text { - Order appropriate diagnostic studies such as Complete Blood Count, microscopy of sputum and sputum culture } \\
\text { - Order Chest X-ray. } \\
\text { - Construct a differential diagnosis which includes transmissible pulmonary infections such as pneumonic plague. } \\
\text { exposed to pathogens in the arena. } \\
\text { - Identify the fact that the patient's husband and sister are also coughing. } \\
\text { - Realize the potential risk of pneumonic plague transmission to healthcare workers and initiate respiratory precautions. } \\
\text { - Provide supportive care including oxygen. } \\
\text { - Initiate appropriate antibiotic therapy. } \\
\text { - Contact appropriate health officials }\end{array}$ \\
\hline Personnel/Props & $\begin{array}{l}\text { - High-fidelity patient simulator. } \\
\text { - Actor- patients husband. } \\
\text { - Actress- patient's sister. } \\
\text { - Actress voice of the simulator. } \\
\text { - A streak of blood for the corner of the patient's mouth to simulate hemoptysis. } \\
\text { - Chest X-ray consistent with pneumonic plague (such X-rays can be found on Google images). } \\
\text { - Resuscitative equipment such as oxygen by mask or endotracheal tube at the discretion of the simulation director. }\end{array}$ \\
\hline Additional literature & $\begin{array}{l}\text { Inglesby TV, Dennis DT, Henderson DA (2000) Plague as a biological weapon. JAMA 283: 2281-2290. } \\
\text { Kman NE, Nelson RN (2008) Infectious agents of Bioterrorism: a review for emergency physicians. Emerg Med Clin N Am } 26: 517-547 .\end{array}$ \\
\hline Competencies addressed & $\begin{array}{l}\text { - Patient care. } \\
\text { - } \text { Medical knowledge. } \\
\text { - Systems-based practice. }\end{array}$ \\
\hline Debriefing points & $\begin{array}{l}\text { - This is a difficult diagnosis. An important purpose of a medical simulation experience is to present and discuss rare diagnoses so } \\
\text { that learners and clinicians can become familiarized. If the participants have initiated antibiotic therapy and respiratory precautions, } \\
\text { they may well have performed valuable medical service in a real similar situation. } \\
\text { - Plague infection as a result of a terrorist attack would be different than natural infection. Bubonic plague is the most common form } \\
\text { of plague seen in the natural world whereas pneumonic plague would be the most likely seen in a terrorist attack. } \\
\text { - A terrorism attack with plaque would most likely occur via an aerosol of Yersinia Pestis. } \\
\text { - The possible diagnoses of plague may at first be overlooked given clinical similarity to other pneumonias. } \\
\text { - Symptoms would occur } 1 \text { to } 6 \text { days after exposure with death following soon after the onset of symptoms if the exposed patients are } \\
\text { untreated; the fatality rate for patients is high when treatment is delayed for greater than } 24 \text { hours. } \\
\text { - The first signs of illness are expected to be fever with cough and dyspnea. The production of bloody, watery or purulent sputum } \\
\text { along with gastrointestinal symptoms may also occur. } \\
\text { - Chest x-ray findings in pneumonic plague are variable but bilateral infiltrates or consolidation are likely. } \\
\text { - Symptomatic patients should be placed in respiratory isolation. } \\
\text { The first clinical suspension of plague must lead to notification of health departments and local or state officials. Many hospitals } \\
\text { such study. } \\
\text { - Antibiotic options for pneumonic plague include streptomycin, which is used infrequently United States; only modest supplies are } \\
\text { available. Gentamycin is a off label second choice. Tetracycline Doxycycline are also FDA approved for plague. Other medications } \\
\text { which have been used to treat plague include tetracyclines, and fluoroquinolones and chloramphenicol. } \\
\text { - A seven-day course of doxycycline is recommended for postexposure prophylaxis. }\end{array}$ \\
\hline
\end{tabular}

Table 1: Bioterrorism - pneumonic plague.

mechanism. Healthcare provider familiarity with plague is low in the developed world, hence ability to diagnose and mange the first victims of a weaponized plague attack may be suboptimal. Since victims of pneumonic plague may deteriorate very rapidly, early diagnosis would be essential in the event of an attack. The use of training with a simulated patient diagnosis of pneumonic plague may be a valuable addition to a bioterrorism management plan.

\section{References}

1. Nishiura $\mathrm{H}$ (2006) Epidemiology of a primary pneumonic plague in Kantoshu Manchuria, from 1910 to 1911: statistical analysis of individual records collected by the Japanese Empire. Int J Epidemiol 35: 1059-1065.

2. Mittal V, Bhattacharya D, Rana UV, Rai A, Pasha ST, et al. (2006) Prompt laboratory diagnosis in timely containment of a plague outbreak in India. J Commun Dis 38: 317-324. 
Citation: Olsen M (2014) Teaching Bioterrorism Preparedness with Simulation - The Pneumonic Plague Example. J Clin Res Bioeth 5: 164. doi:10.4172/2155-9627.1000164

Page 4 of 4

3. SPECK RS, WOLOCHOW H (1957) Studies on the experimental epidemiology of respiratory infections. VIII. Experimental pneumonic plague in Macacus rhesus. J Infect Dis 100: 58-69.

4. Centers for Disease Control (CDC) (1992) Pneumonic plague--Arizona, 1992. MMWR Morb Mortal Wkly Rep 41: 737-739.

5. Werner SB, Weidmer CE, Nelson BC, Nygaard GS, Goethals RM, et al. (1984) Primary plague pneumonia contracted from a domestic cat at South Lake Tahoe, Calif. JAMA 251: 929-931.

6. Alsofrom DJ, Mettler FA Jr, Mann JM (1981) Radiographic manifestations of plaque in New Mexico, 1975-1980. A review of 42 proved cases. Radiology 139: 561-565.

7. Ketai L, Alrahji AA, Hart B, Enria D, Mettler F Jr (2003) Radiologic manifestations of potential bioterrorist agents of infection. AJR Am J Roentgenol 180: 565-575.

8. Hartwig KA, Burich D, Cannon C, Massari L, Mueller L, et al. (2009) Critical challenges ahead in bioterrorism preparedness training for clinicians. Prehosp Disaster Med 24: 47-53.

9. Niska RW, Burt CW (2007) Terrorism preparedness: have office-based physicians been trained? Fam Med 39: 357-365.

10. Griswold S, Ponnuru S, Nishisaki A, Szyld D, Davenport M, et al. (2012) The emerging role of simulation education to achieve patient safety: translating deliberate practice and debriefing to save lives. Pediatr Clin North Am 59: 13291340.

11. Singer BD, Corbridge TC, Schroedl CJ, Wilcox JE, Cohen ER, et al. (2013) First-year residents outperform third-year residents after simulation-based education in critical care medicine. Simul Healthc 8: 67-71.

12. Coolen EH, Draaisma JM, Hogeveen M, Antonius TA, Lommen CM, et al (2012) Effectiveness of high fidelity video-assisted real-time simulation: a comparison of three training methods for acute pediatric emergencies. Int $\mathrm{J}$ Pediatr 2012: 709569.

13. Quraishi SA, Kimatian SJ, Murray WB, Sinz EH (2011) High-fidelity simulation as an experiential model for teaching root cause analysis. J Grad Med Educ 3: $529-534$.

14. Littlewood KE, Shilling AM, Stemland CJ, Wright EB, Kirk MA (2013) High-fidelity simulation is superior to case-based discussion in teaching the management of shock. Med Teach 35: e1003-1010.

15. Keegan RD, Brown GR, Gordon A (2012) Use of a simulation of the ventilatorpatient interaction as an active learning exercise: comparison with traditional lecture. J Vet Med Educ 39: 359-367.

16. Seybert AL, Smithburger PL, Kobulinsky LR, Kane-Gill SL (2012) Simulation-based learning versus problem-based learning in an acute care pharmacotherapy course. Simul Healthc 7: 162-165.
17. Eason MP (2013) Sarin exposure: a simulation case scenario. South Med J 106: 55-62.

18. Olsen ME (2013) Use of medical simulation to teach bioterrorism preparedness: the anthrax example. South Med J 106: 49-54.

19. Kman NE, Nelson RN (2008) Infectious agents of bioterrorism: a review for emergency physicians. Emerg Med Clin North Am 26: 517-547, x-xi.

20. Centers for Disease Control and Prevention (CDC) (2006) Human plague--four states, 2006. MMWR Morb Mortal Wkly Rep 55: 940-943.

21. Bossi P, Tegnell A, Baka A, Van Loock F, Hendriks J, et al. (2004) Bichat guidelines for the clinical management of plague and bioterrorism-related plague. Euro Surveill 9: E5-6.

22. Inglesby TV, Dennis DT, Henderson DA, Bartlett JG, Ascher MS, et al. (2000) Plague as a biological weapon: medical and public health management Working Group on Civilian Biodefense. JAMA 283: 2281-2290.

23. Centers for Disease Control and Prevention (2005) Plague Medical Management Training Module. [Assessed May 21, 2013]

24. Waterer GW, Robertson H (2009) Bioterrorism for the respiratory physician Respirology 14: 5-11.

25. Davis CJ (1999) Nuclear blindness: An overview of the biological weapons programs of the former Soviet Union and Iraq. Emerg Infect Dis 5: 509-512.

26. Cosgrove SE, Perl TM, Song X, Sisson SD (2005) Ability of physicians to diagnose and manage illness due to category A bioterrorism agents. Arch Intern Med 165: 2002-2006.

27. Centers for Disease Control (CDC) (1992) Pneumonic plague--Arizona, 1992 MMWR Morb Mortal Wkly Rep 41: 737-739

28. Cicero MX, Auerbach MA, Zigmont J, Riera A, Ching K, et al. (2012) Simulation training with structured debriefing improves residents' pediatric disaster triage performance. Prehosp Disaster Med 27: 239-244.

29. Raemer D, Anderson M, Cheng A, Fanning R, Nadkarni V, et al. (2011) Research regarding debriefing as part of the learning process. Simul Healthc 6 Suppl: S52-57.

30. Hart D, McNeil MA, Griswold-Theodorson S, Bhatia K, Joing S (2012) High fidelity case-based simulation debriefing: everything you need to know. Acad Emerg Med 19: E1084.

31. Rudolph JW, Simon R, Raemer DB, Eppich WJ (2008) Debriefing as formative assessment: closing performance gaps in medical education. Acad Emerg Med 15: 1010-1016. 